\title{
Guidelines for online learning
}

Here are some guidelines to prepare us for our online learning journey together!

These guidelines help us to think through the following questions:

1. How can we best prepare ourselves and our surroundings for online learning?

2. How can we stay on track - even if we don't have reliable Internet access all of the time?

3. Will we have access to course material

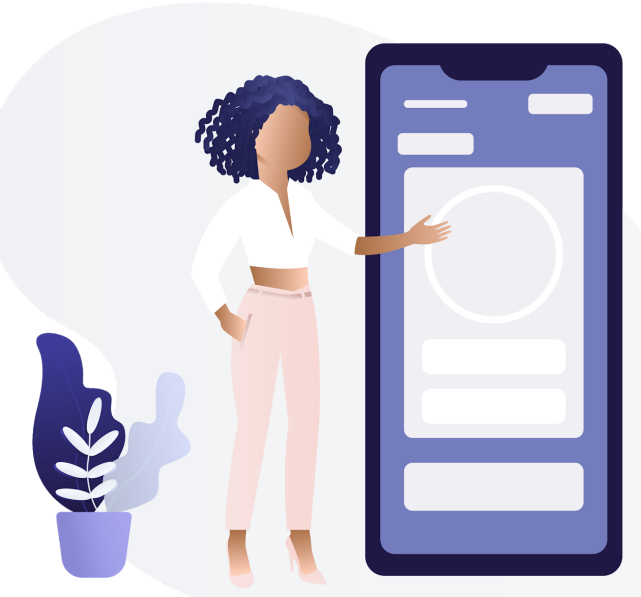
and notes?

4. How will we know what to do, and by when?

5. What kinds of support is available to us when we may want to ask for help?

\section{How can we best prepare ourselves and our surroundings for online learning?}

\subsection{Be kind to our bodies}

During a seminar or lecture we take for granted our ability to look and move around. With online learning, our focus is likely to be drawn to a single, stationary point (such as a laptop or mobile phone). This has physical implications for our bodies.

\section{TIPS:}

- Stay mindful of your posture: To avoid stiff necks and aching shoulders, we need to do regular check-ins with your bodies: Is your chin always tiled down toward your device, your shoulders slightly hunched, or your legs crossed? Try to adjust your chair or device so that you are looking straight when facing a screen, your shoulders are relaxed and both feet comfortably planted on the floor. 
- Move around: For good blood circulation and focus, you can take a break every 20-25 minutes. (You can even set a timer, which will ensure you are more productive during that block of learning time). During your break, move around or stretch, drink some water and breathe deeply.

- Rest your eyes: Every few minutes focus on another object, farther beyond your screen. Looking around close proximity and lighting of technological devices can put strain on the eyes).

\subsection{Engage the support of family members to help you succeed.}

- Consider your study space (especially if you are at your home): If you are studying online in a space shared with others (e.g. at home), let those you are sharing the space with you know. If your family, friends, housemates know you are learning online, they will understand that you may have to carve out time for study in times of the day they might normally assume you are available for other activities.

- Consider your peers: Connect with peers in your courses and help each other stay on track. If you need assistance or have a question, you are likely to get a quicker response from a peer than from one of the official communication channels where your query may be among many.

- Consider your colleagues: If you are studying during working hours, let your closest colleagues, collaborators and line manager know. You can even commit to sharing a short report with them on what you have learned, and how it can be applied to their professional context. You can also consult the document for 'Tips for Online Communication"

\section{Are there ways to ensure we stay on track - even if we don't have reliable Internet access all of the time?}

\subsection{Prepare for learning without Internet/Wi-Fi}

Use your time wisely when you do have a reliable Internet connection and download/copy and save any course materials, forum instructions, etc to work through when you're offline. You can even download audio podcasts or videos on your mobile device, so that you can listen to these offline. You can also save content of course sites on the RUconnected App and then you can engage with the materials offline.

\subsection{Plan for dedicated 'study block sessions'}

This resource is licensed under a CC BY 4.0 International license. Attribution: Centre for Higher Education Research, Teaching and Learning (CHERTL), Rhodes University, Makhanda (Grahamstown), SA. 
Distraction and other responsibilities can easily get in the way of online learning. Structure has been a usual part of our studies up to now. See the document on 'Getting ready for online learning' for some strategies. To structure your learning time, you could start by doing the following:

\section{Diarise time for learning:}

In order to keep up your learning momentum over the next few weeks, decide before the start of the course at which times in each week you plan to dedicate to online learning. Make a provisional note in your calendar or diary for each of these time slots.

2. Note important course dates:

As soon as you receive announcements on RUconnected and updated course outlines with important dates, add these to your diary or calendar. Most of your work will be asynchronous that you can attend to when it is suitable for you but you may have some live or synchronous sessions with your lecturer and your classmates. Also schedule sufficient time to prepare tasks or assignments, before the deadline. You may have formative assessment tasks designed for learning purposes.

\section{Try to minimise distractions:}

Although it may be tempting to check your email or phone, you will gain most value from the course if you commit to brief but focused spurts of engagement: To do this, you could consider the Pomodoro technique, i.e. setting a timer for 25 minutes and focusing completely on the coursework. When the timer goes off, take a short 5 minute break, and then focus on your course work again for another 25 minutes. If you do this a few times, you'll

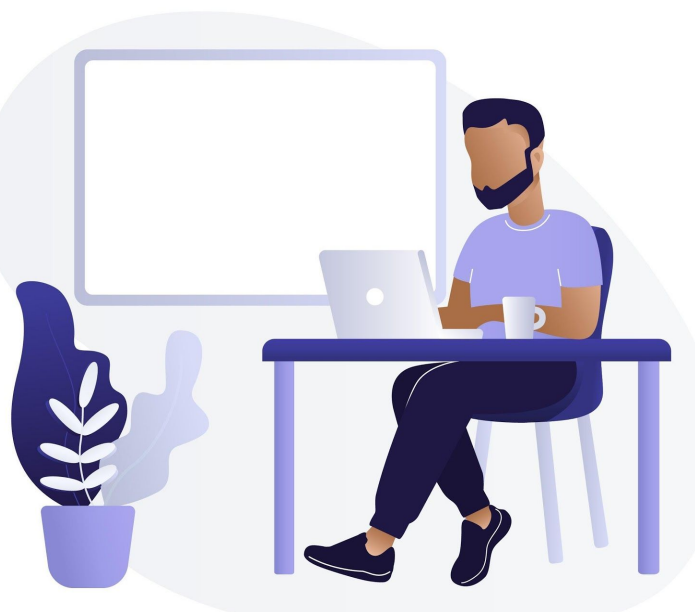
have completed a considerable amount of work in a 'study block session'. 


\section{Will we have access to course material and notes?}

Even though we are moving online for all learning, you will still have access to all the usual course materials and notes. These will be updated and uploaded by your lecturers. You will need to ensure that you are able to access and download materials from your course sites. Should anything be missing please contact your lecturer or tutor for the relevant course.

\section{How will we know what to do, and by when?}

You will need to navigate to your specific course site, where you should be able to read information (provided by your lecturer) about various formative assessment tasks and their due dates. If you can't find this information, you should contact your lecturer or tutor to confirm these details.

\section{What kinds of support is available to us when we may want to ask for help?}

Online learning can seem daunting, please don't hesitate to ask for help. You can consult the document for 'Support for Online Learning' which go beyond the below:

- For administrative queries, please contact your relevant course coordinator/lecturer/tutor.

- For device and internet related queries, email the IT student help desk studentsupport@ru.ac.za

- For RUconnected and RUconnected app related queries, email edtech@ru.ac.za

- Counselling centre counsellingcentre@ru.ac.za

- If you have concerns about your health or Covid-19, please visit: https://www.ru.ac.za/cvrtt/ and/or https://sacoronavirus.co.zal 